\title{
MANAGEMENT OF LUMBAR SPINAL STENOSIS
}

\author{
FRANCO POSTACCHINI \\ From the University of Modena, Italy
}

\section{DEFINITION OF TERMS}

The term stenosis means a narrowing of the calibre of an orifice or a tube. It causes a decreased flow of fluids or gasses within the tube or compression of its solid contents (Verbiest 1976). In the case of the spinal canal, the term indicates a pathological condition causing compression of the contents of the canal, particularly the neural structures. If compression does not occur, the canal should be described as narrow but not stenotic.

I have defined lumbar spinal stenosis as a "narrowing of the osteoligamentous vertebral canal and/or the intervertebral foramina causing compression of the thecal sac and/or the caudal nerve roots; at a single vertebral level, narrowing may affect the whole canal or part of it" (Postacchini 1983). This definition distinguishes between disc herniation and stenosis. A disc prolapse does cause stenosis, in the strictest sense, but the two conditions are so different in their pathogenesis and anatomical and clinical characteristics that they cannot be considered as a single pathological entity.

The lumbar spinal canal consists of a central part, two lateral parts and a posterior part corresponding to the interlaminar angle. The central portion is the so-called central spinal canal, and each lateral part constitutes the nerve-root or radicular canal.

The central spinal canal is rounded and occupied by the thecal sac. Stenosis of this portion is sometimes called central spinal stenosis to distinguish it from lateral spinal stenosis (nerve-root canal stenosis). This terminology implies that in central spinal stenosis the nerve-root canals may not be stenotic, but this is not the case. Stenosis of the central portion is almost always associated with stenosis of the lateral corners of the spinal canal. The term 'spinal canal stenosis' is therefore preferable to central spinal stenosis.

The nerve-root canal is the semitubular structure through

F. Postacchini, MD, Professor of Orthopaedic Surgery

Clinica Ortopedica Policlinico, University of Modena, Largo del Pozzo 71, 41100 Modena, Italy.

Printed with the permission of EFORT. The article appears in European Instructional Course Lectures Vol. 2, 1995. which the nerve root runs from the thecal sac to the intervertebral foramen. The proximal part of the canal, also called the subarticular or intervertebral portion, is limited anteriorly by the intervertebral disc and posterolaterally by the superior articular process and the facet joint. The distal part of the canal corresponds to the lateral recess, i.e., the lateral corner of the vertebral foramen at the level of the pedicle. Pathological narrowing of the nerve-root canal not associated with stenosis of the central spinal canal is called isolated nerve-root (or radicular) canal stenosis.

The entrance and exit of the intervertebral foramen lie at the medial and lateral borders of the pedicle. Some authors (Wiltse 1984; Burton 1987) include the intervertebral foramen in the nerve-root canal, of which it is then the most distal portion. In my opinion there are valid anatomical reasons for distinguishing between the two and identifying stenosis of the intervertebral foramen as a separate condition.

\section{CLASSIFICATION}

Spinal canal stenosis (or central stenosis) has primary, secondary and combined forms (Postacchini 1989). Primary stenosis may be congenital, or developmental, when it is due to defective postnatal development of the lumbar vertebrae. The latter includes achondroplastic stenosis and constitutional stenosis. Primary stenosis is characterised by compression of the neural structures which is entirely due to the congenital or developmental narrowing. In secondary stenosis the spinal canal is developmentally normal and compression is due to an acquired condition such as spondylotic changes which may or may not be associated with degenerative spondylolisthesis, Paget's disease or the late sequelae of vertebral fractures. The term 'combined stenosis' describes those cases in which primary narrowing of the spinal canal is associated, at the same vertebral level, with secondary narrowing, generally spondylotic in nature.

Isolated nerve-root canal stenosis and stenosis of the intervertebral foramen may also be primary, secondary or combined. Secondary and combined forms are by far the most common.

\section{PATHOMORPHOLOGY}

In the rare forms of stenosis resulting from congenital malformations, fractures or metabolic bone diseases, the spinal canal may be constricted either at the level of the vertebra or 


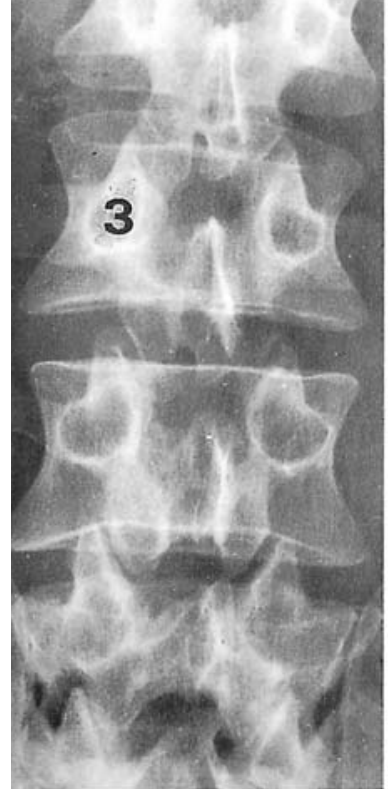

Fig. 1a

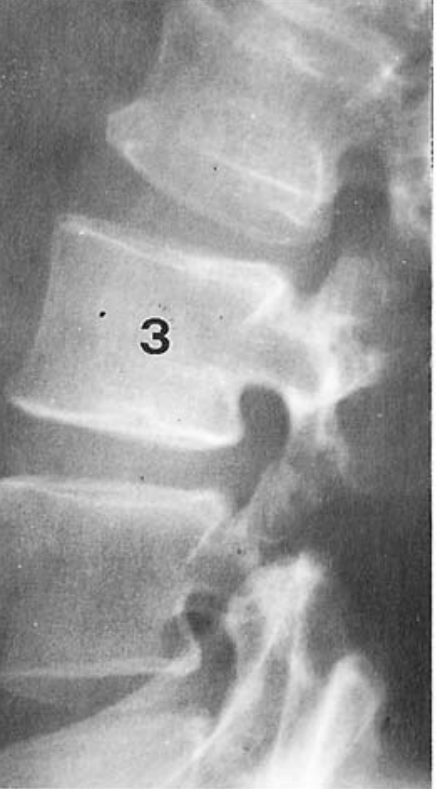

Fig. 1b
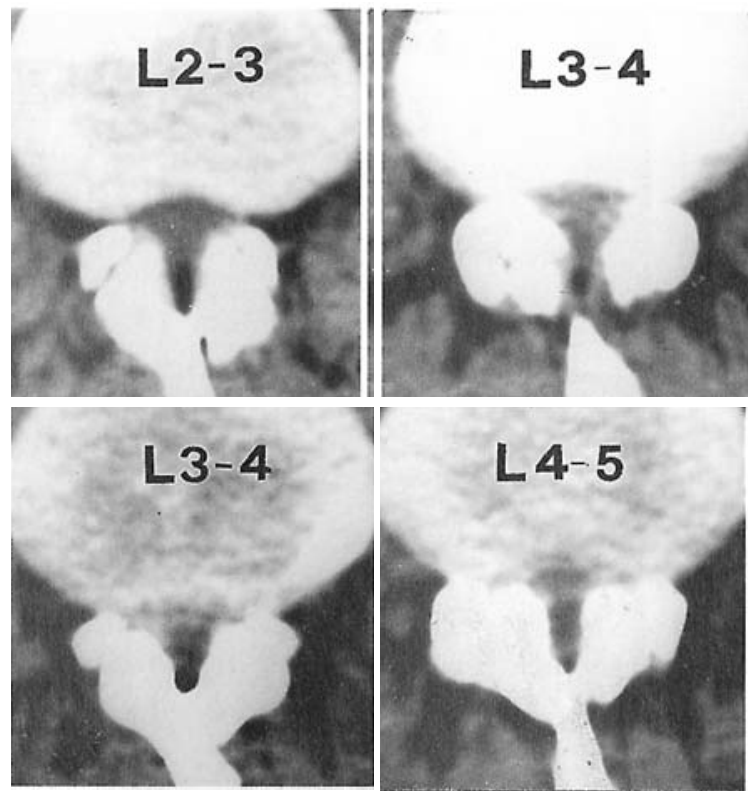

Fig. 1c

Achondroplasic stenosis. Figures 1a and 1b - Plain radiographs showing the most typical characteristics of the achondroplasic lumbar spine: short laminae, narrow interapophysolaminar spaces, short pedicles, marked concavity of the posterior surface of the vertebral body. Figure 1c - CT showing abnormal narrowing of the spinal canal in the transverse plane with resultant compression of the nervous structures.

of the intervertebral space, but in all other forms of stenosis compression of the neural structures occurs only at the intervertebral levels, where lie the structures (intervertebral disc, vertebral end plates, articular processes and ligamenta flava) which may undergo degenerative changes. The portion of the canal situated between the two end plates of a single vertebra may be narrow, but not stenotic.

The nerve-root canal is also commonly constricted above the level of the pedicle.

Achondroplastic stenosis. The characteristic features of achondroplastic vertebrae are their increased thickness, the reduced length of the pedicles, and the marked concavity of the posterior surfaces of the vertebral bodies in the sagittal plane. The intervertebral discs are usually normal in height, but their posterior surfaces bulge into the spinal canal.

In transverse section the vertebral canal has a narrow interarticular diameter, while the midsagittal diameter is usually normal (Fig. 1). These features are due to malformation of the pedicles, shortening of the laminae, and the abnormal orientation of the laminae and articular processes.

Constitutional stenosis. Two types of stenosis may be identified. In one the vertebrae show morphological characteristics similar to those of achondroplasia (see Fig. 5). In the other there is an abnormally short midsagittal diameter of the spinal canal (less than $11.5 \mathrm{~mm}$ in the Caucasoid race; Postacchini, Ripani and Carpano 1983) but the interpedicular distance is normal (Fig. 2). In this type, the laminae usually lie more transversely than normal, producing flattening of the canal in the sagittal plane. In both types the intervertebral discs often bulge into the canal, the articular processes may be hypertrophic from degenerative changes, and the interapophysolaminar spaces, occupied by the ligamenta flava, are abnormally narrow.

Degenerative stenosis. The anatomical changes include hypertrophy of the articular processes, thickening of the ligamenta flava, and disc degeneration, sometimes associated with posterior osteophytosis of the vertebral body.

Hypertrophy of the inferior articular process may cause narrowing of the central portion of the spinal canal; that of the superior articular process contributes to the deformation of the central portion of the canal and narrows the intervertebral portion of the nerve-root canal (see Fig. 6). Hypertrophy of the superior articular process may also produce narrowing of the intervertebral foramen and, if there is disc resorption, its apical portion may impinge on the nerve root in the foramen.

The ligamenta flava are usually shortened in the vertical and transverse planes and thickened. The shortening is due to loss of disc height and hypertrophy of the articular processes; the thickening results from the shortening and from degenerative changes in the ligamentous tissue (Postacchini et al 1993a,b). The thickened ligamenta flava cause narrowing of the central portion of the spinal canal and of the intervertebral portion of the nerve-root canals.

The intervertebral disc usually shows some degree of degeneration and resorption. The latter condition is often associated with posterior osteophytes on the vertebral bodies that narrow both the central spinal canal and the nerveroot canal. In isolated root-canal stenosis the intervertebral disc often bulges posteriorly and contributes to the compression of the nerve root.

Combined stenosis. For congenital or developmental reasons the midsagittal diameter of the vertebral canal is at or 

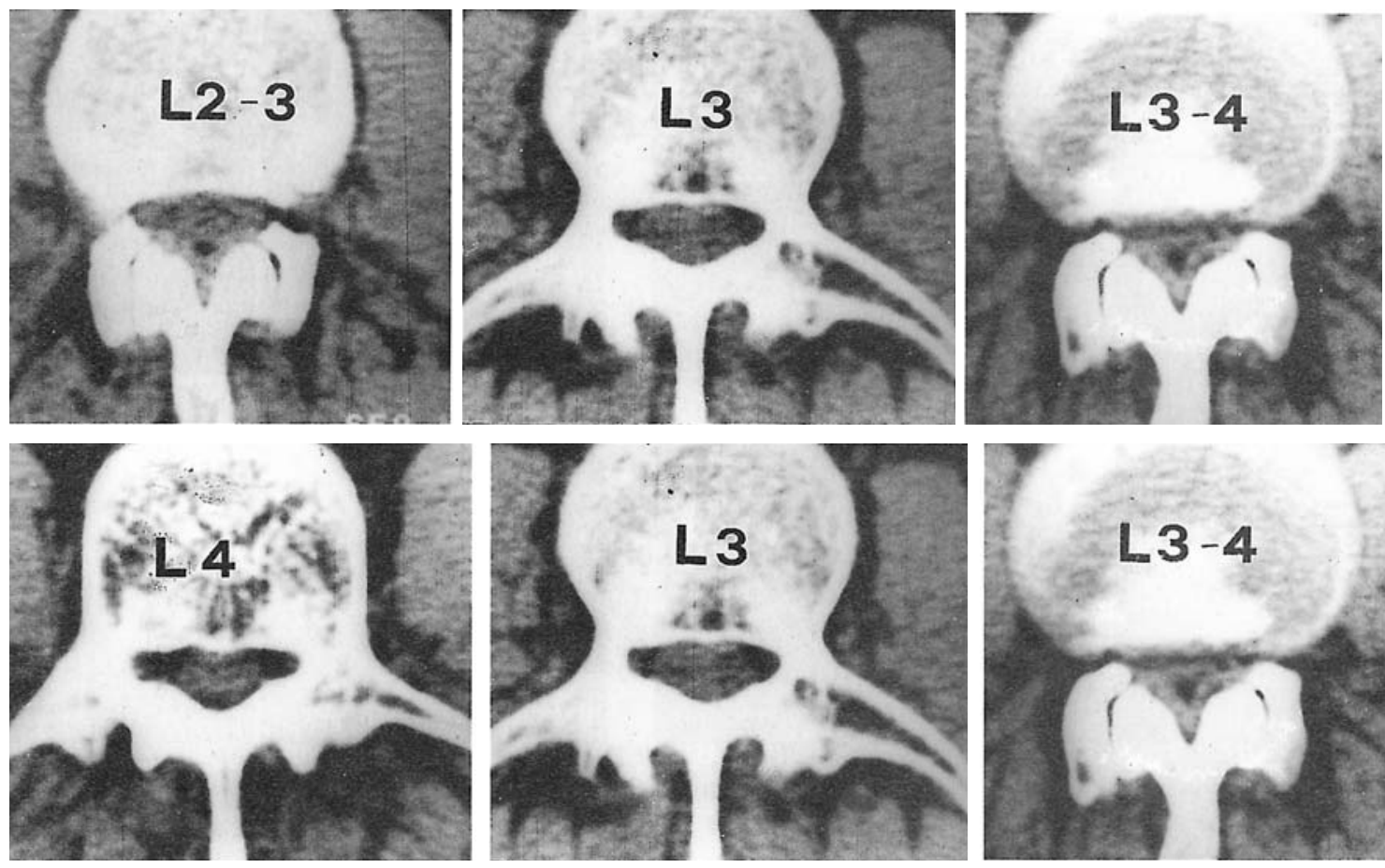

Fig. 2

Constitutional stenosis at L2-L3 to L4-L5. At L3 and L4 the interpedicular distance is large, while the midsagittal diameter is abnormally short, thus giving the spinal canal a flattened appearance. The nervous structures are compressed at the intervertebral levels.

slightly below the lower limit of normal. The spondylotic changes are similar to, but usually milder than, those found in purely degenerative forms of stenosis. Even minor degenerative changes can cause severe neural compression in a developmentally narrow spinal canal.

Degenerative spondylolisthesis. Degenerative spondylolisthesis causes narrowing of the spinal canal and/or the nerve-root canals.

When the degree of slip is mild, narrowing is mainly caused by the associated arthritic changes. These cause hypertrophy of the articular processes and alter their shape and orientation. Degeneration of the superior articular processes of the vertebra below the slip usually causes narrowing only of the nerve-root canals. When, however, outgrowth of the medial border of the processes is severe, they may also encroach on the spinal canal. The hypertrophied inferior articular processes of the slipped vertebra constrict the posterior portion of the central spinal canal.

When the degree of slip is severe the articular processes are often orientated more sagittally than normal, suggesting that this orientation predisposes to severe slipping. The emerging nerve roots may then be trapped between the inferior articular processes of the slipped vertebra and the posterosuperior border of the vertebra below (Fig. 3). The latter vertebra is responsible for anterior compression of the thecal sac; posterior compression is due to the entire posterior arch of the slipped vertebra (Fig. 4).

The effects of spondylolisthesis depend on the original dimensions of the spinal canal. If the canal is wide, com- pression of the thecal sac may not occur even with severe slip. When the dimensions are normal or less than normal there may be severe compression from mild degenerative changes or slight vertebral slipping.

\section{CONSERVATIVE TREATMENT}

Conservative treatment is by physiotherapy, anti-inflammatory drugs and the use of a lumbar corset. Calcitonin has also been used in patients with intermittent claudication. The hormone may produce an arterial shunt that reduces the skeletal blood flow and improves the circulation of the deprived cauda equina (Porter and Hibbert 1983).

There have been few reports of the results of conservative treatment. Tile et al (1976) described unsatisfactory results in 11 of 14 patients but the severity of the stenosis and the length of follow-up were not recorded. Of 23 patients treated conservatively by Hause et al (1977), more than half improved, but neurological deficits seldom recovered. Hawkes and Roberts (1980) found that six of nine patients treated with lumbar corsets had remission of their symptoms.

Of 41 patients treated with calcitonin (Porter and Hibbert 1983), 11 had improvement of radicular symptoms and could walk further. Most of them, however, had no neurological deficit and myelography, when performed, had shown only mild compression of the neural structures.

In my experience, most patients with severe central spinal stenosis either do not improve or have only tempo- 


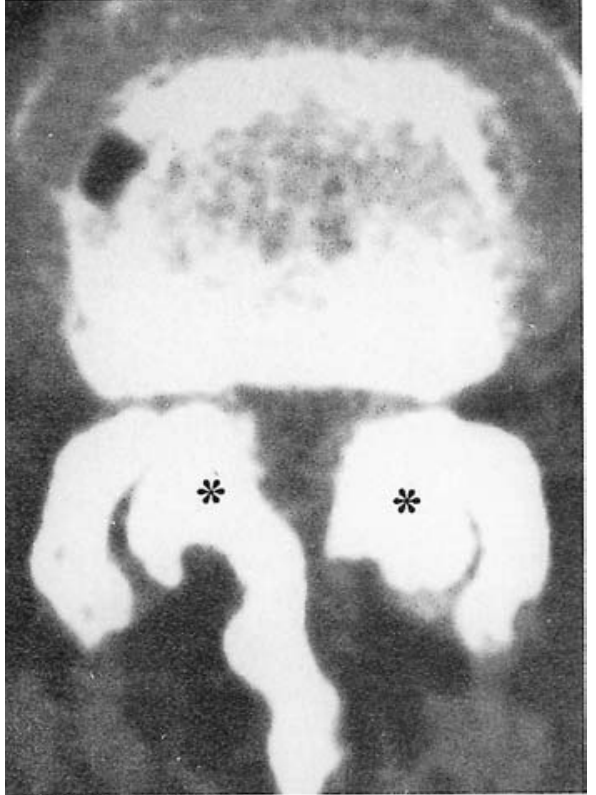

Fig. 3

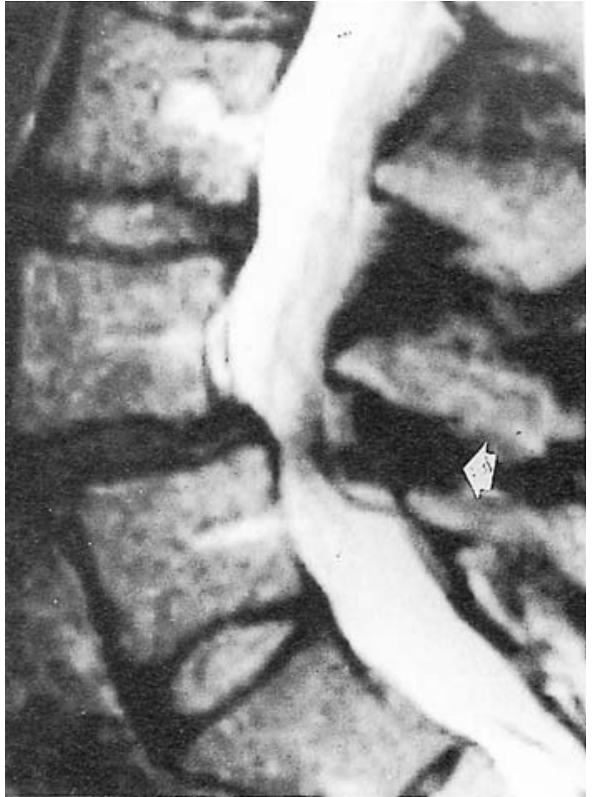

Fig. 4

Figure 3 - CT of L4 vertebra with severe degenerative olisthesis. The inferior articular processes of the olisthetic vertebra $(* *)$ narrow not only the central portion of the spinal canal, but also the nerve-root canals due to hypertrophy and ventral subluxation. Figure 4 - MRI of a patient with degenerative spondylolisthesis of L4. The thecal sac is compressed anteriorly by the posterosuperior border of the vertebral body of L5. Posteriorly, it is constricted by the posterior arch of L4 and the ligamenta flava (arrow) attached to its ventral surface.

rary relief with conservative treatment. Patients with only posterior or posterolateral compression of the thecal sac, however, often improve, probably as a result of the natural course of the disease. This is also true for isolated nerveroot canal stenosis. If narrowing of the radicular canal is severe and there are significant neurological changes, conservative treatment usually does not help.

\section{SURGICAL TREATMENT}

\section{Indications}

Spinal canal stenosis. Surgical treatment is indicated in patients with moderate or marked compression of the nerve roots. The greater the degree of compression the better the chance of a satisfactory result, provided that the motor deficit is not very severe and long-standing. In such cases the symptoms may be relieved, but the paralysis improves only partially or not at all.

The patient with a narrow canal, but no stenosis, does not need surgery and it is rarely indicated for mild or moderate posterior or posterolateral indentation of the thecal sac if the nerve roots are not compressed. Nor is surgery required when the leg symptoms are vague and inconstant, or if the main symptom is claudication, but the patient can still walk several hundred metres or more. Indeed, in such patients it is often difficult to be sure that an extraspinal condition or a spinal condition other than stenosis is not the cause. Decompressive surgery is also usually contraindicated in patients whose radicular symptoms and signs do not correlate with the level of nerve-root compression as revealed by imaging studies. It should be remembered that spinal stenosis may be asymptomatic, and that evidence of compression of nerve roots on imaging studies is not a guarantee of clinical success after decompression.

The best candidate for surgery is the patient with severe osteoligamentous compression of the neural structures, severe leg symptoms, moderate or no neurological deficit and, except for patients with degenerative spondylolisthesis, little or no back pain. In degenerative spondylolisthesis back pain may be the most prominent symptom but excellent results can nevertheless be obtained by decompression and fusion, particularly if the slipped vertebra has been shown to be hypermobile by flexion-extension radiographs.

Isolated nerve-root canal stenosis. Surgery is appropriate when clinical findings or imaging studies clearly indicate compression of a nerve root in its radicular canal. Often, protrusion of a disc produces symptoms in a clinically silent osteoligamentous compression of the root. Isolated disc resorption causes compression of an emerging root only exceptionally and rarely represents an indication for surgery.

Stenosis of the intervertebral foramen. This condition is often seen on CT or MRI but in most cases narrowing of the foramen does not cause compression of the nerve root. Decompression is only indicated if there is protrusion or bulging of the intervertebral disc.

\section{Planning of surgery}

Method of decompression. Surgery aims to decompress the nervous structures, particularly the nerve roots in their 


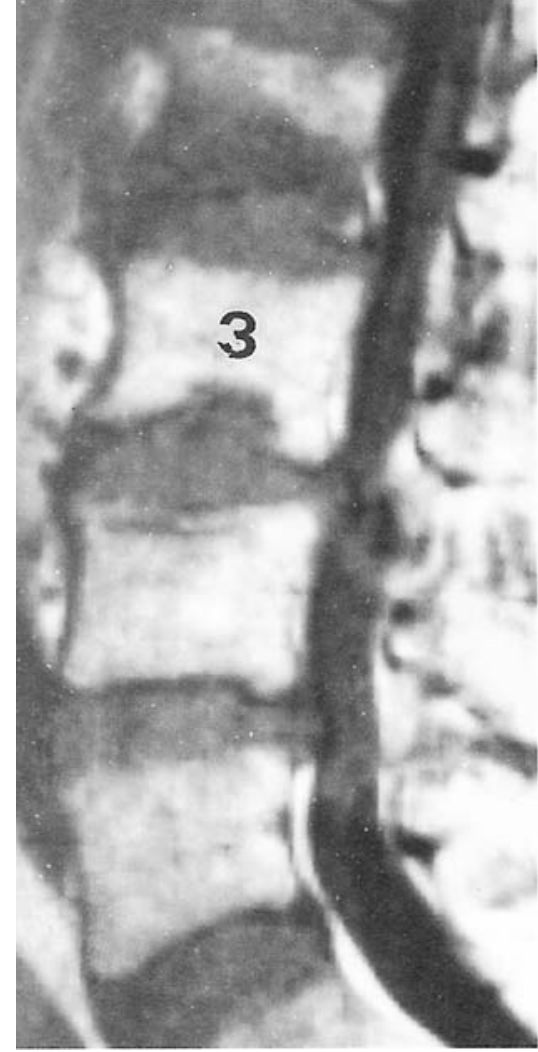

Fig. 5a
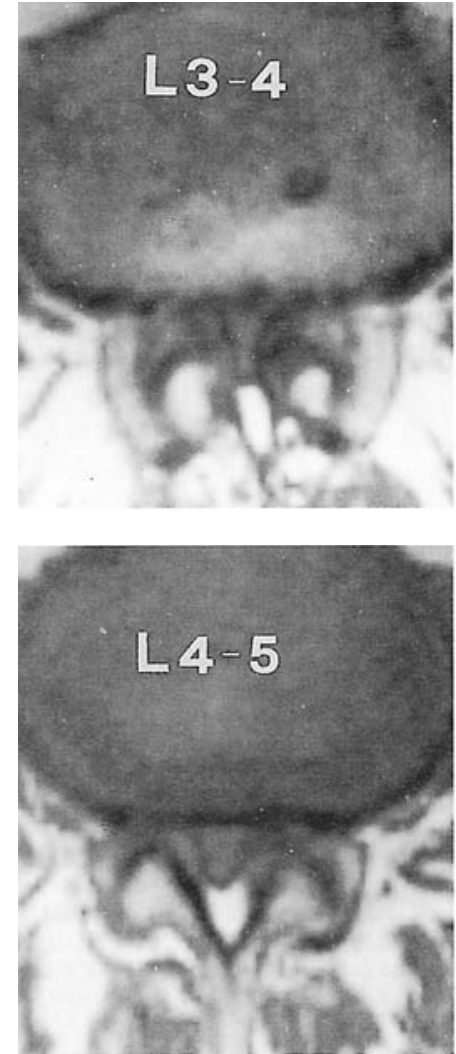

Fig. 5b

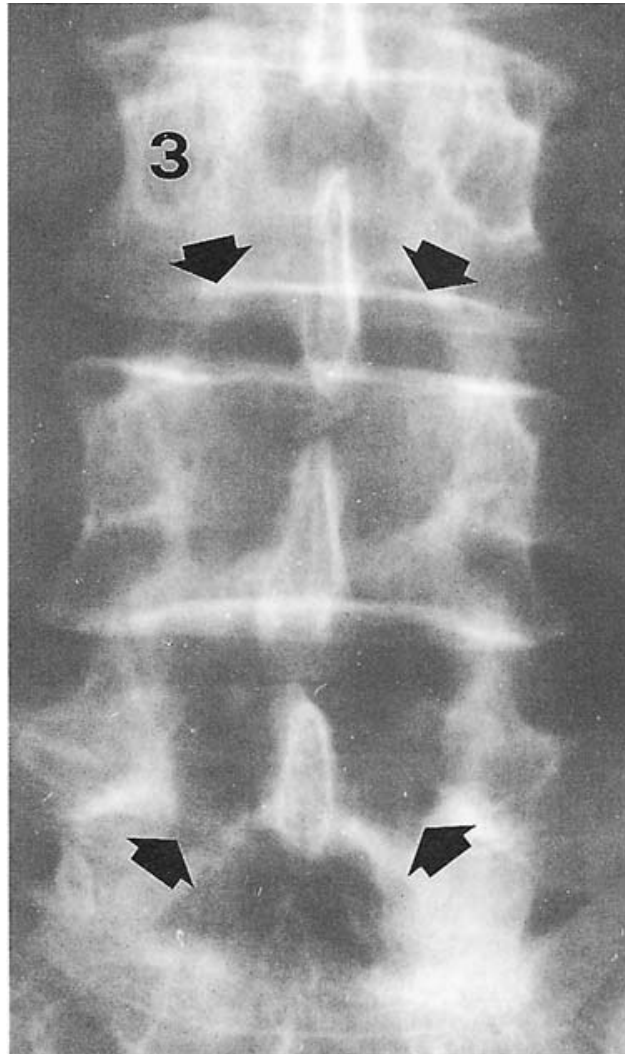

Fig. $5 \mathrm{c}$

A patient with constitutional stenosis at L3-L4 and L4-L5. Figure 5a - T1-weighted MRI showing narrowing of the thecal sac at L3 to L5 and constriction of the sac at L3-L4. The third and fourth lumbar discs protrude posteriorly. Figure $5 \mathrm{~b}-$ MRI showing transverse narrowing of the spinal canal causing compression of the nervous structures. Figure $5 \mathrm{c}-\mathrm{AP}$ radiograph after bilateral laminectomy at the stenotic levels.

extrathecal course, without compromising vertebral stability. Preservation of a stable spine is of paramount importance because the relief of symptoms in the leg may not satisfy the patient if back pain develops or is made worse.

In the last few years the technique of multiple laminotomy has been widely used because it preserves vertebral stability better than total laminectomy. There is,

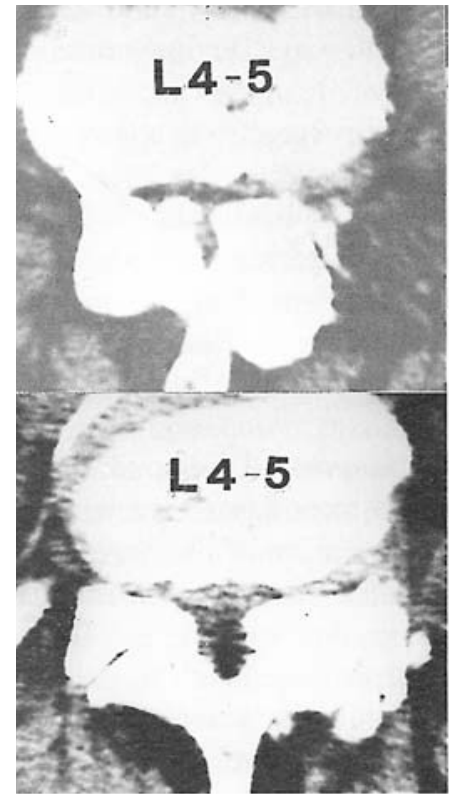

Fig. 6a

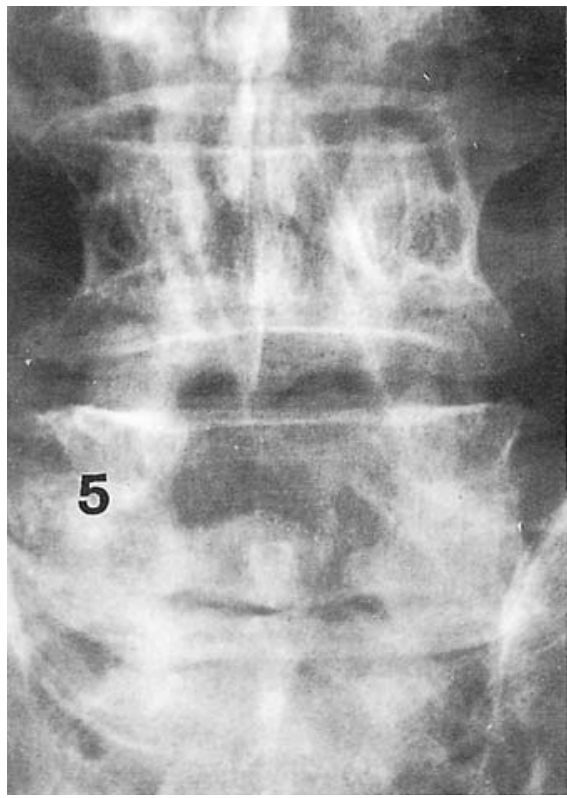

Fig. $6 \mathrm{~b}$
Figure $6 \mathrm{a}-\mathrm{CT}$ of a patient with severe degenerative stenosis at L4-L5 level. The central portion of the spinal canal and the nerve-root canals are narrowed by degenerative changes of both superior and inferior articular processes. Figure $6 \mathrm{~b}-\mathrm{AP}$ radiograph after total laminectomy and undercutting facetectomy at L4-L5. 


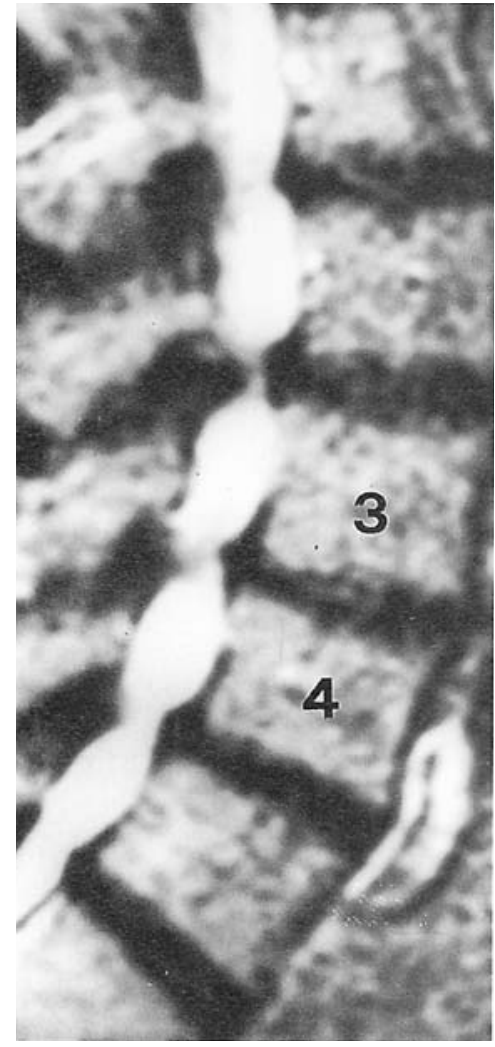

Fig. 7a

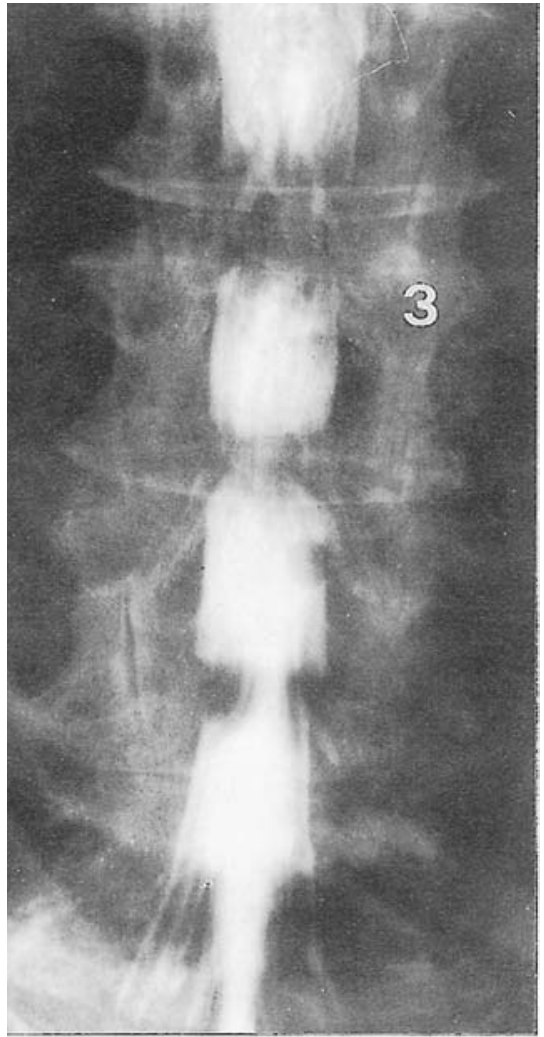

Fig. 7b

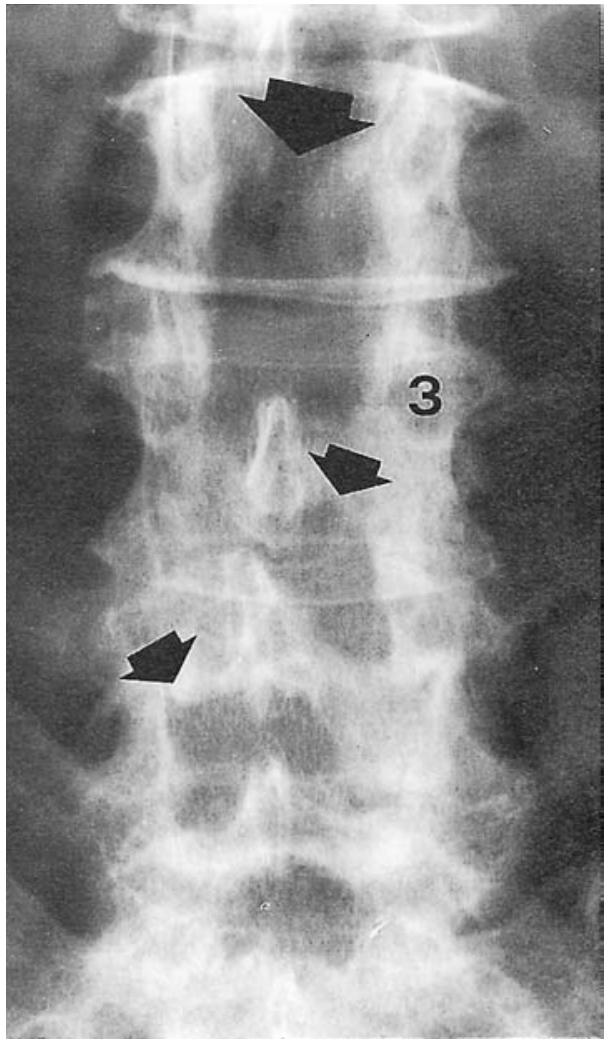

Fig. 7c

A patient with marked spinal canal stenosis at L2-L3 and severe root-canal stenosis at L3-L4 and L4-L5, who had total laminectomy at L2-L3 and laminotomy at L3-L4 on the left and L4-L5 on the right. Figure 7a - Preoperative MRI. Figure 7b - Preoperative myelogram. Figure 7c - Postoperative radiograph.

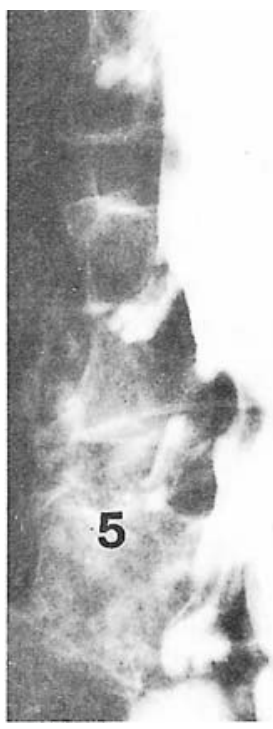

Fig. 8a
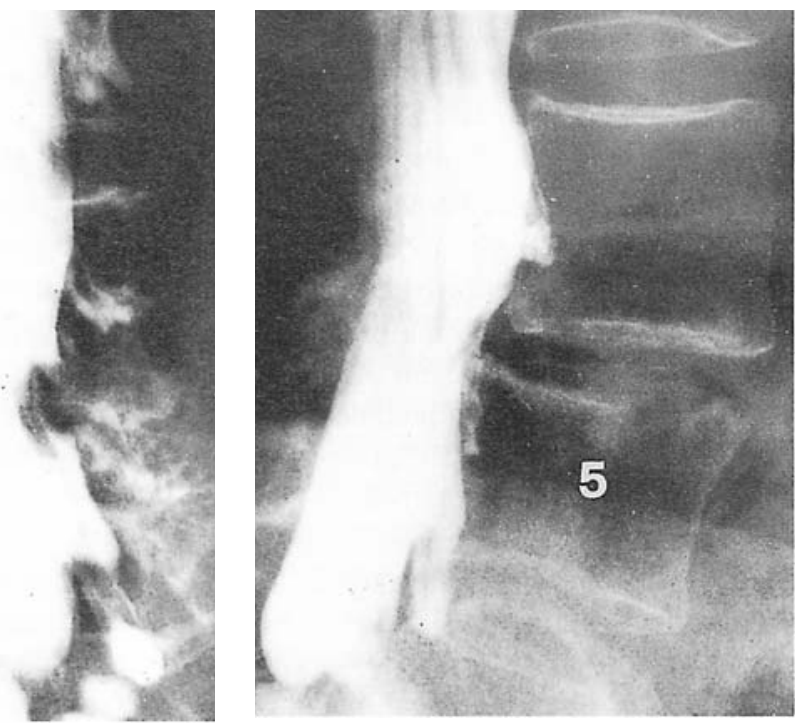

Fig. $8 \mathrm{~b}$

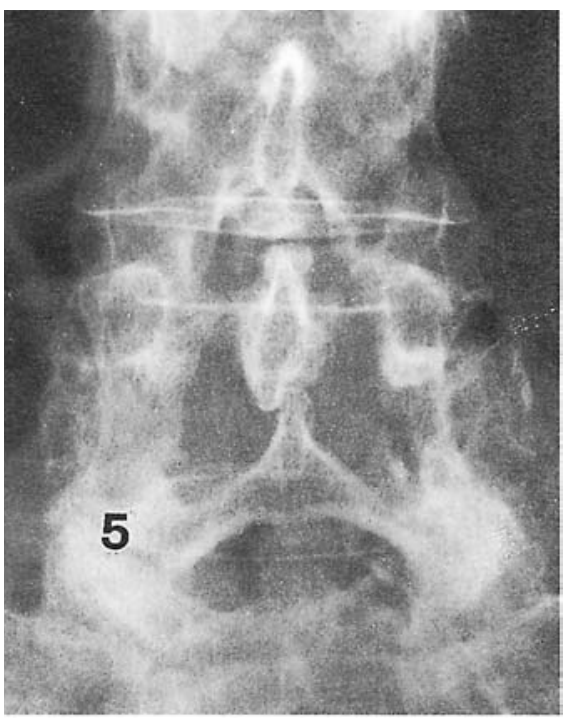

Fig. $8 \mathrm{c}$

A patient with mild degenerative spondylolisthesis of L4 and nerve-root canal stenosis at the L4-L5 levels in whom a bilateral laminotomy (c) was carried out.

however, still a role for the latter since it sometimes allows more effective neural decompression. Multiple laminotomy is the best treatment for developmental stenosis since the patients are usually middle-aged, the stenosis is rarely severe and disc excision is often necessary (Fig. 5). It is also preferred for degenerative or combined stenosis when narrowing of the spinal canal is mild or moderate, particularly if disc excision has been planned. Total laminectomy 


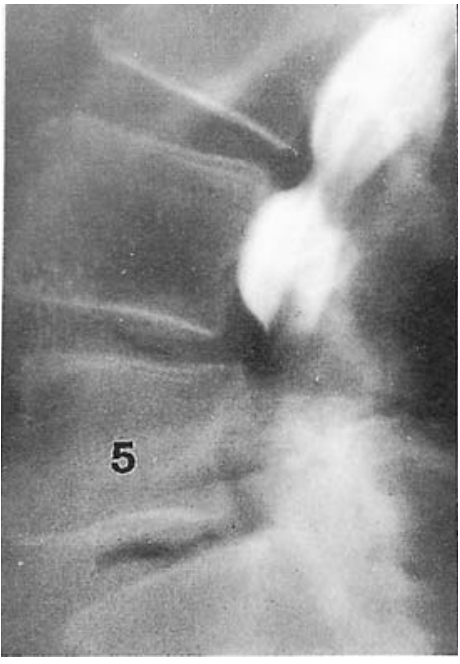

Fig. 9a

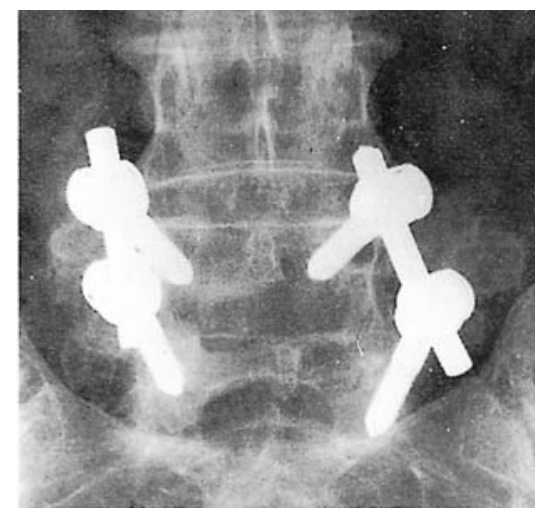

Fig. 10a

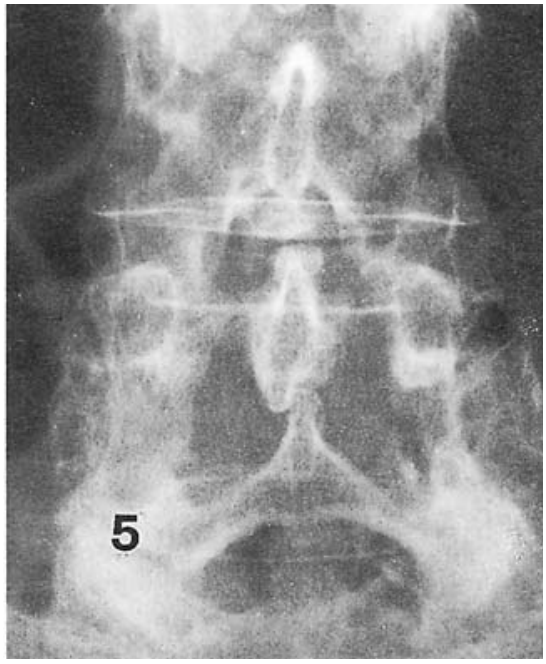

Fig. 9b

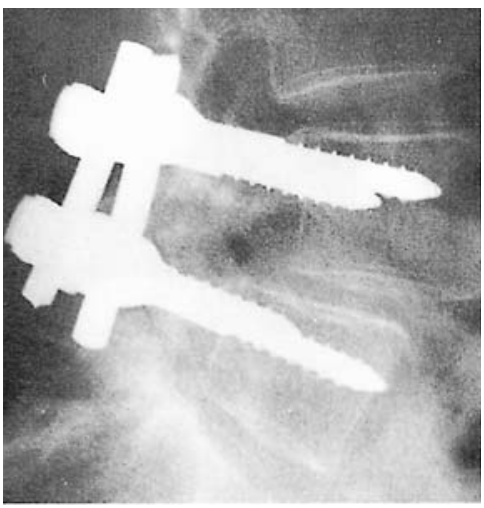

Fig. 10b
A patient with degenerative spondylolisthesis of L4 and L5 causing a complete myelographic block at L4-L5 (a) who had total laminectomy at L3 to L5 and (b) intertransverse process fusion at L4-S1.
Total laminectomy and bilateral intertransverse process fusion with internal fixation (compact CD system) for degenerative spondylolisthesis of L4 and spinal canal stenosis at L4-L5 level. is usually more effective for severe stenosis, provided that the involved segments are stable preoperatively (Fig. 6). When they are unstable, the choice is between multiple laminotomy and total laminectomy with fusion. In some patients both types of decompression may be used at different levels (Fig. 7).

Degenerative spondylolisthesis. There are conflicting opinions on whether decompression alone is as satisfactory as decompression and fusion. Bilateral laminotomy, or even total laminectomy, may be carried out without concomitant fusion for mild spinal canal stenosis, or any degree of radicular canal stenosis, in patients with mild spondylolisthesis, no vertebral hypermobility on functional radiographs, and mild or no back pain (Fig. 8). Similarly, after total laminectomy in elderly patients with moderate spondylolisthesis and severe resorption of the discs below, there is usually no indication for fusion. On the other hand, if there is moderate or severe slip, vertebral hypermobility (even of mild degree) and/or severe spinal canal stenosis, decompression should be followed by fusion (Fig. 9). The addition of a fusion encourages the surgeon to decompress as widely as necessary without the fear of symptomatic postoperative instability.

In degenerative spondylolisthesis of $\mathrm{L} 4$, the arthrodesis may be performed only at the L4-L5 level or it may include the lumbosacral joint. Extension of the fusion to the sacrum puts greater mechanical stresses on the mobile vertebra above and it may subsequently become unstable. A 'floating fusion', however, has as good a chance of sound union as an extended fusion, particularly if pedicle screws are used (Brodsky et al 1989; Kabins et al 1992), and it should be preferred.

Transpedicular fixation is used to increase the chance of bone fusion while diminishing the need for prolonged postoperative immobilisation. Fixation may be on one or both sides (Figs 10 and 11). Bilateral fixation provides greater stability, but causes higher functional stresses on the adjacent segments. Unilateral fixation has less morbidity and has been found to give results as good as those from bilateral fixation (Kabins et al 1992). I mostly use unilateral instrumentation if there is mild olisthesis and mild or no preoperative hypermobility; bilateral fixation is used in patients with moderate or severe hypermobility.

Anatomical reduction of the slipped vertebra does not 


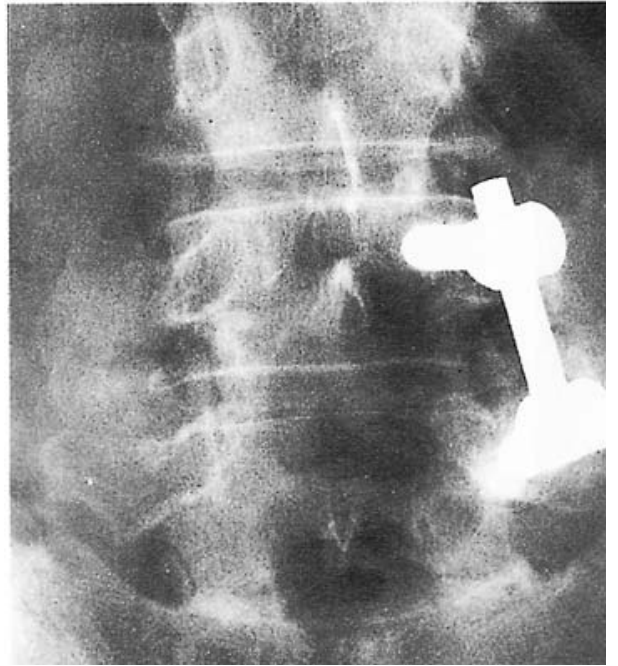

Fig. 11a

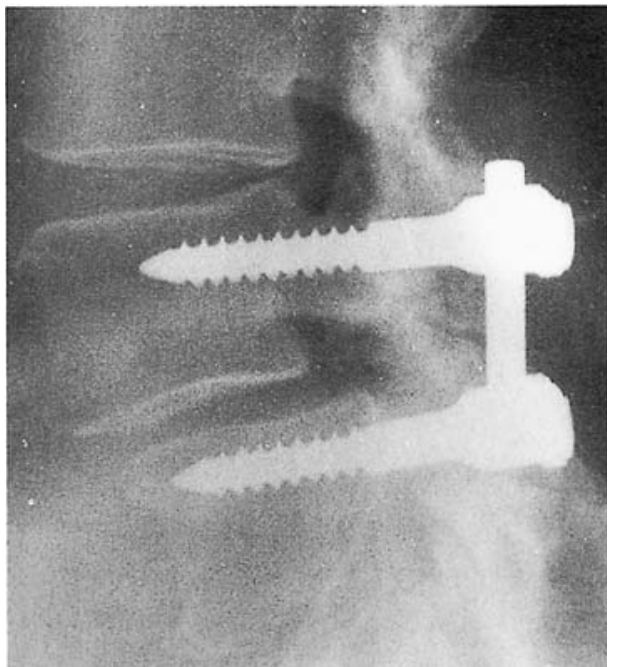

Fig. 11b

Total laminectomy, bilateral intertransverse process fusion and unilateral internal fixation (compact CD system) for degenerative spondylolisthesis of L4 and spinal canal stenosis at L4-L5 level.

seem to improve the clinical results of surgery.

Scoliosis. If there is severe lumbar scoliosis as well as stenosis, total laminectomy may not sufficiently relieve compression of the caudal nerve roots which are at risk from pedicle and facet migration and rotation. Furthermore, decompression may cause the scoliosis to increase or give rise to lateral vertebral slipping. These risks should deter the use of simple decompressive surgery. If operation is undertaken, it should be followed by spinal fusion after correction of the scoliosis using transpedicular screws.

Prophylactic decompression. In patients with stenosis at many levels it may be difficult to determine whether one or several levels are responsible for the symptoms and signs. When this is the case, all stenotic levels should be decompressed. I have had to reoperate on several patients in whom stenosis at a lumbar level which was not decompressed at the initial operation was the cause of persistence or recurrence of radicular symptoms (Fig. 12).

If there is mild stenosis at levels contiguous to an area of severe stenosis, prophylactic decompression of the asymptomatic levels may be considered. The decision depends on the patient's age, the site and degree of stenosis and the presence or not of disc abnormalities and vertebral instability. In very old patients it is usually unnecessary but in the middle-aged it is generally better to decompress adjacent areas of mild stenosis since there is a high risk of them becoming symptomatic later from degenerative changes. This advice holds particularly if there is no risk of vertebral instability resulting from the more extensive decompression.

\section{Surgical technique}

Multiple laminotomy. Extreme caution is required when performing laminotomy if the spinal canal is stenotic or if disc excision is required because the nerve roots emerging from the thecal sac are easily injured when the spinal canal is approached from the lateral side (Postacchini et al 1993b). Use of an operating microscope may diminish the risk of nerve-root injury. Young, Veerapen and O'Laoire (1988) reported a low incidence of dural tears (9\%) with the microsurgical technique, and in my experience dural tears are less likely if a microscope is used. If laminotomy provides inadequate decompression, total laminectomy should be performed.

Care should be taken not to fracture the pars interarticularis. This complication, which is more likely to occur during multiple laminotomy than during total laminectomy, may give rise to greater instability than results from excision of the central portion of the posterior arch. If fracture of the pars interarticularis occurs on both sides of a single vertebra the posterior arch should be excised and spinal fusion performed.

Laminectomy. If laminectomy has to be done at several levels, either total laminectomy of the involved vertebrae can be carried out, or the spinal canal can be 'recalibrated' as described by Senegas et al (1988). This technique consists of removing only that part of the posterior vertebral arch which lies at the level of the intervertebral space, leaving intact the portion opposite the middle of the vertebral body. The residual bone bridge, however, often breaks and, in any case, stability depends on the integrity of the interspinous and supraspinous ligaments, which are removed by this technique.

Extent of decompression. The results of operative treatment may deteriorate with time due to gradual regrowth of the resected posterior arch (Postacchini and Cinotti 1992) (Fig. 13). This is more likely to occur when a narrow decompression is performed. In the longitudinal direction, decompression should extend as far as half the height of the vertebra above and below the stenotic area. In the transverse direction, decompression should be continued until the emerging 


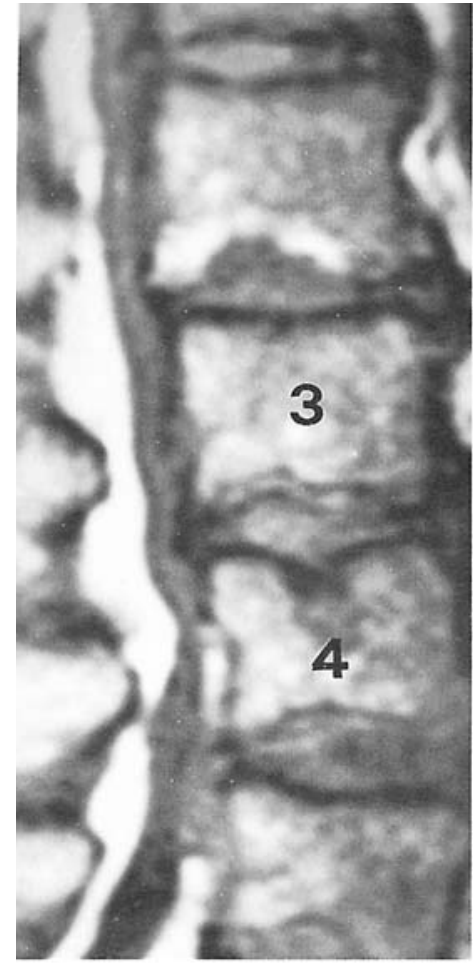

Fig. 12a

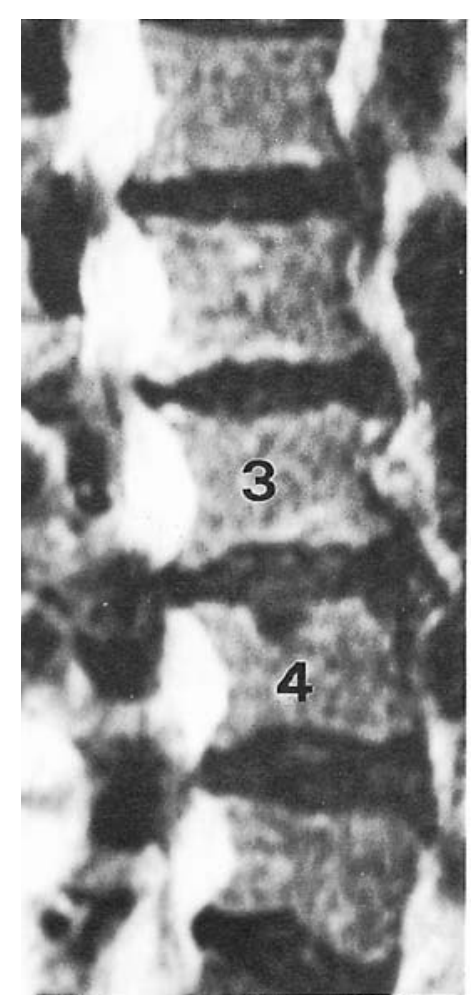

Fig. 12b

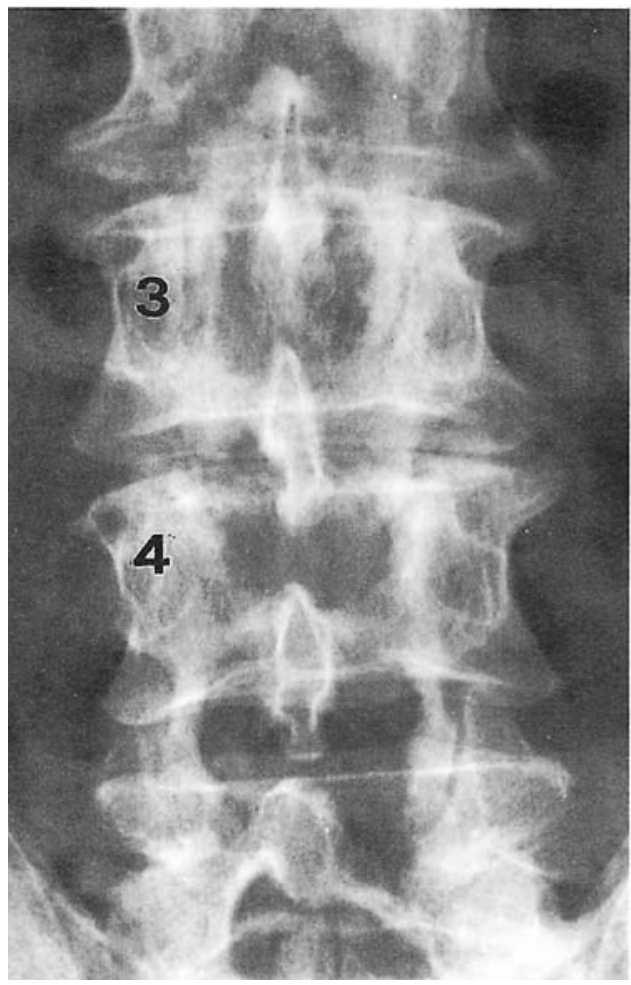

Fig. 12c

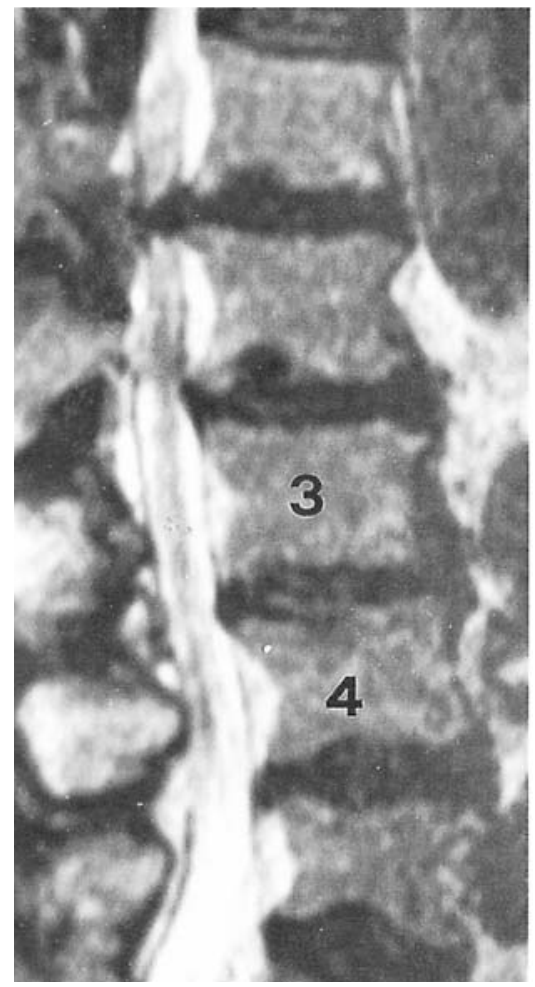

Fig. 12d

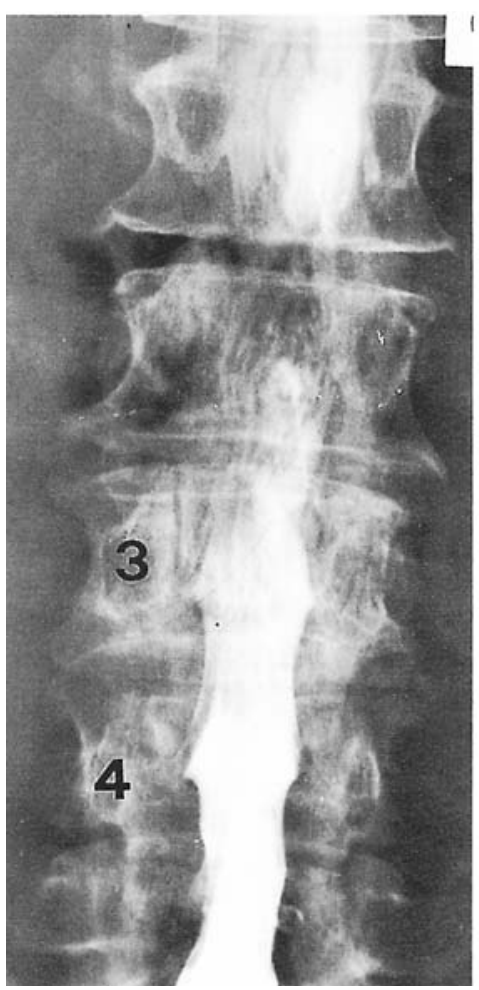

Fig. 12e

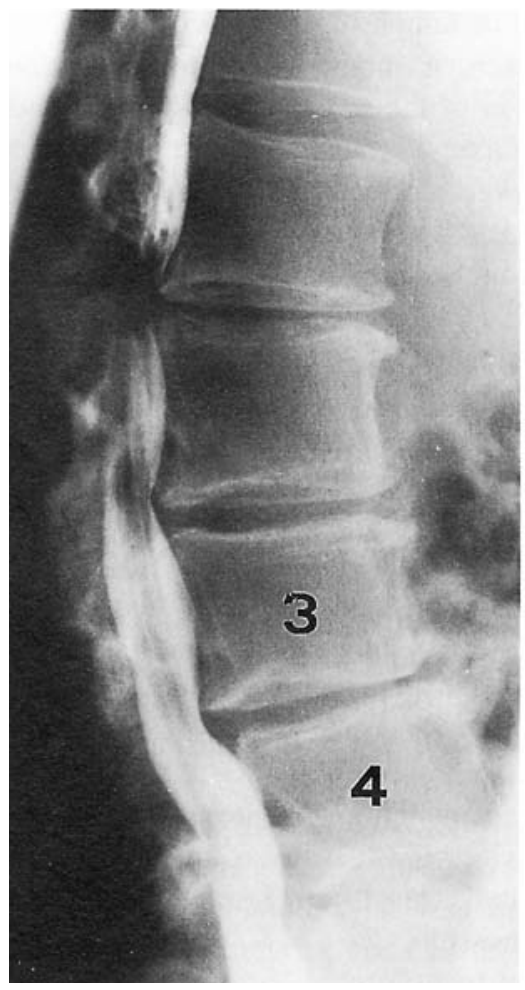

Fig. 12f

A patient who had a combined spinal canal stenosis at L1 to L5. Preoperative MRI showed compression of the nervous structures at the first four lumbar levels (a and b), but compression at L1-L2 was considered relatively mild. Bilateral laminotomy was performed at L2-L3 to L4-L5 (c). One year after surgery radicular symptoms recurred. MRI (d) and myelograms (e and f) showed no persistent compression of the nervous structures at the operated levels, but there was a severe neural constriction (more marked than preoperatively) at L1-L2, which required further surgery. 
root is visible and free from compression.

The nerve root is rarely compressed in the intervertebral foramen, even when the latter appears to be constricted on imaging studies. To detect root compression, a probe is introduced into the foramen along the nerve root. Arthrectomy should be performed only when there is definite radicular compression. If bilateral arthrectomy is performed at the same level, an arthrodesis should generally be carried out.

Arthrectomy. Partial arthrectomy can be performed with does not bulge significantly, but should be carried out if there is severe bulging of an abnormally soft disc. This situation is found particularly in developmental central stenosis and in isolated nerve-root canal stenosis, when a bulging, or herniated, disc may contribute significantly to neural compression.

\section{RESULTS}

Spinal canal stenosis. Conflicting opinions are found in

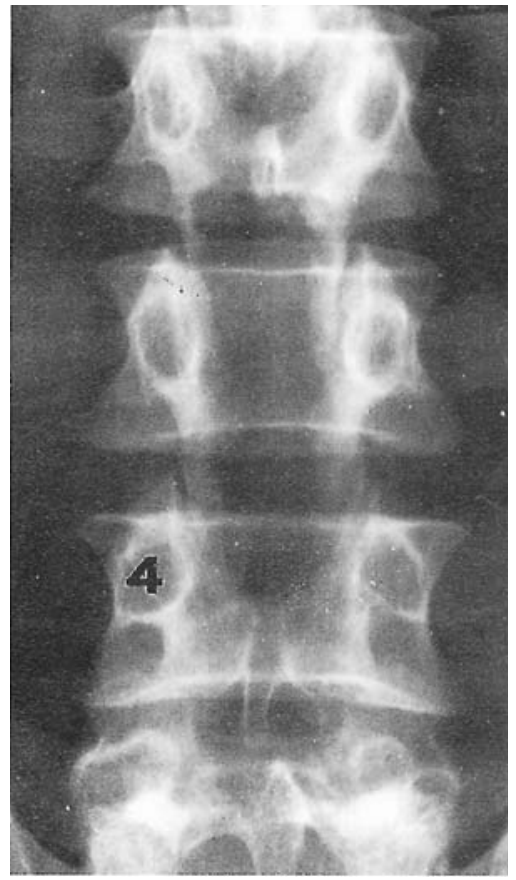

Fig. 13a

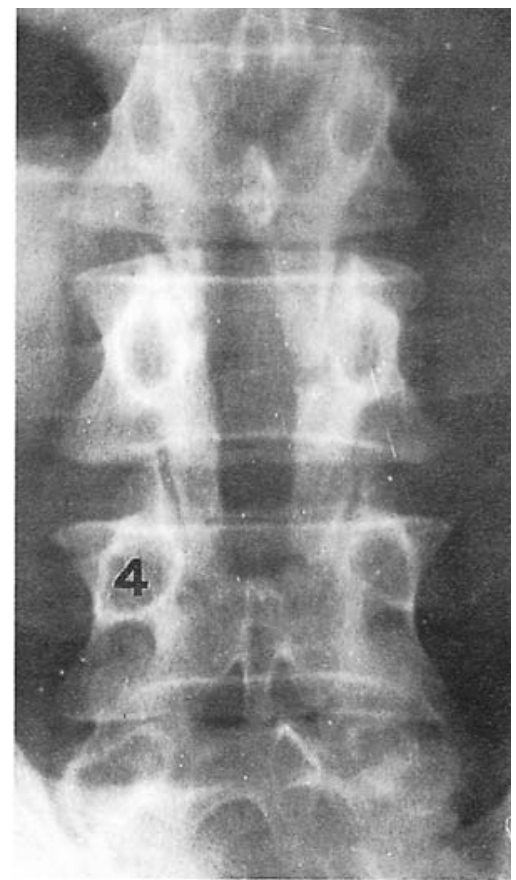

Fig. 13b

Radiographs showing regrowth of the posterior vertebral arch after central laminectomy at L3 to L5 immediately after surgery (a) and seven years later (b).

rongeurs or osteotomes. The osteotome is preferred when total laminectomy is performed because it allows easier undercutting of the facet, which is the best method of facetectomy. In severe stenosis, however, it may be difficult to perform an undercutting facetectomy without damaging the nerve root and in these cases the inferior facet may be excised by osteotome and the superior facet by rongeur in such a way as to remove the facet obliquely. When performing bilateral decompression, at least the outer third of the articular process should be preserved on both sides.

Discectomy. The traditional concept is that discectomy should not generally be performed in spinal stenosis because removal of the posterior longitudinal ligament and annulus fibrosus increases the risk of instability. In my experience, standard discectomy performed unilaterally rarely causes instability if the spine is stable preoperatively. Discectomy should not be performed if the disc is hard and the numerous studies that have analysed the outcome of surgical treatment for spinal stenosis (Paine 1976; Verbiest 1977; Lassale, Deburge and Benoist 1985; Hopp and Tsou 1988; Postacchini 1989; Herron and Mangelsdorf 1991; Katz et al 1991; Postacchini et al 1993a,b; Cinotti, Postacchini and Weinstein 1994). The following conclusions, however, can be reached. In the short term approximately $80 \%$ of patients have a satisfactory outcome, but about $20 \%$ of these deteriorate later. Radicular pain and intermittent claudication are the symptoms most often relieved by operation. If several levels are decompressed there is a higher risk of failure than if the operation is at a single level. Patients with severe stenosis have as good or better results than those with mild stenosis. Old age does not spoil the quality of the result. Subtotal or total arthrectomy is associated with a high incidence of postoperative instability, but too limited removal of the articular processes risks 
persistence or recurrence of radicular symptoms. Patients who have had previous decompression of the spine are less likely to have a good result. Comorbidity is associated with poor results. About $10 \%$ of patients undergo a second operation, usually because of instability or recurrent stenosis.

Isolated nerve-root canal stenosis. In most series, satisfactory results were obtained in more than $90 \%$ of patients who had laminotomy (Choudhury and Taylor 1977; Aryanpur and Ducker 1990). In one series (Kirkaldy-Willis et al 1982), the patients in whom a disc herniation had been associated with stenosis had a higher proportion of excellent results than those with stenosis alone. I found satisfactory results in $83 \%$ of 43 patients followed for an average of three years (Postacchini 1989). The group of patients with preoperative neurological deficits had better results than the group with no deficits.

Degenerative spondylolisthesis. The proportion of satisfactory results after decompression alone has ranged from $83 \%$ to $87 \%$ (Cauchoix, Benoist and Chassaing 1976; Epstein et al 1983; Herron and Trippi 1989). If spinal fusion, with or without instrumentation (not transpedicular), was added there were good or excellent results in $88 \%$ to $100 \%$ of patients (Lombardi et al 1985; Hanley 1986; Kaneda et al 1986; Knox et al 1989). Few studies, however, have directly compared fused and unfused patients. Herkowitz and Kurz (1991), in a prospective study comparing 25 unfused and 25 fused patients (without instrumentation), found satisfactory results in $44 \%$ of the first group, and in $96 \%$ of the second. In two studies the results of pedicle screw fixation for degenerative spondylolisthesis were satisfactory in 83\% (Bridwell et al 1993) and 88\% (Chang and McAfee 1988) of cases.

The available data and my own experience indicate that, at least in the medium term, decompression and fusion provide better results than decompression alone, particularly if pedicle screw fixation is used. An advantage of this type of fixation is that there is no need for rigid postoperative immobilisation.

\section{REFERENCES}

Aryanpur J, Ducker T. Multilevel lumbar laminotomies: an alternative to laminectomy in the treatment of lumbar stenosis. Neurosurgery 1990;26:429-33.

Bridwell KH, Sedgewick TA, O'Brien MF, Lenke LG, Baldus C. The role of fusion and instrumentation in the treatment of degenerative spondylolisthesis with spinal stenosis. J Spinal Disord 1993;6:461-72.

Brodsky AE, Hendricks RL, Khalil MA, Darden BV, Brotzman TT. Segmental ('floating') lumbar spine fusions. Spine 1989;14:447-50.

Burton CV. On the diagnosis and surgical treatment of lumbar subarticular and 'Faraout' lateral spinal stenosis. In: Watkins RG, Collis JS, eds. Lumbar discectomy and laminectomy. Aspen Public Rockville, Maryland, 1987.

Cauchoix J, Benoist M, Chassaing V. Degenerative spondylolisthesis. Clin Orthop 1976;115:122-9.

Chang KW, McAfee PC. Degenerative spondylolisthesis and degenerative scoliosis treated with a combination segmental rod-plate and transpedicular screw instrumentation system: a preliminary report. $J$ Spinal Disord 1988;1:247-56.

Choudhury AR, Taylor JC. Occult lumbar spinal stenosis. J Neurol Neurosurg Psychiatry 1977;40:506-10.
Cinotti G, Postacchini F, Weinstein JN. Lumbar spinal stenosis and diabetes: outcome of surgical decompression. J Bone Joint Surg [Br] 1994;76-B:215-9.

Epstein NE, Epstein JA, Carras R, Lavine LS. Degenerative spondylolisthesis with an intact neural arch: a review of 60 cases with an analysis of clinical findings and the development of surgical management. Neurosurgery 1983;13:555-61.

Hanley EN. Decompression and distraction-derotation arthrodesis for degenerative spondylolisthesis. Spine 1986;11:269-76.

Hawkes CH, Roberts GM. Lumbar canal stenosis. Br J Hosp Med 1980;23:498, 500, 502-5.

Herkowitz HN, Kurz LT. Degenerative lumbar spondylolisthesis with spinal stenosis: a prospective study comparing decompression with decompression and intertransverse process arthrodesis. J Bone Joint Surg [Am] 1991;73-A:802-8.

Herron LD, Mangelsdorf C. Lumbar spinal stenosis: results of surgical treatment. J Spinal Disord 1991;4:26-33.

Herron LD, Trippi AC. L4-5 degenerative spondylolisthesis: the results of treatment by decompressive laminectomy without fusion. Spine 1989;14:534-8.

Hopp E, Tsou PM. Postdecompression lumbar instability. Clin Orthop 1988;227:143-51.

Kabins MB, Weinstein JN, Spratt KF, et al. Isolated L4-L5 fusions using the variable screw placement system: unilateral versus bilateral. J Spinal Disord 1992;5:39-49.

Kaneda K, Kazama H, Satoh S, Masanori F. Follow-up study of medial facetectomies and posterolateral fusion with instrumentation in unstable degenerative spondylolisthesis. Clin Orthop 1986;203:159-67.

Katz IN, Lipson SJ, Larson MG, et al. The outcome of decompressive laminectomy for degenerative lumbar stenosis. J Bone Joint Surg [Am] 1991;73-A:809-16.

Knox BD, Harvell JC, Nelson PB, Hanley EN. Decompression and Luque rectangle fusion for degenerative spondylolisthesis. J Spinal Disord 1989;2:223-8.

Lassale B, Deburge A, Benoist M. Résultats à long terme du traitement chirurgical des sténoses lombaires opérées. Rev Rhum Mal Osteoartic 1985;52:27-33.

Lombardi JS, Wiltse LL, Reynolds J, Widell EH, Spencer C III. Treatment of degenerative spondylolisthesis. Spine 1985;10:821-7.

Paine KWE. Results of decompression for lumbar spinal stenosis. Clin Orthop 1976;115:96-100.

Porter RW, Hibbert C. Calcitonin treatment for neurogenic claudication. Spine 1983;8:585-92.

Postacchini F. Lumbar spinal stenosis and pseudostenosis: definition and classification of pathology. Ital J Orthop Traumatol 1983;9:339-50.

Postacchini F. Lumbar spinal stenosis. Wien, etc: Springer-Verlag, 1989.

Postacchini F, Cinotti G. Bone regrowth after surgical decompression for lumbar spinal stenosis. J Bone Joint Surg [Br] 1992;74-B:862-9.

Postacchini F, Cinotti G, Gumina S, et al. Long-term results of surgery in lumbar stenosis: 8-year review of 64 patients. Acta Orthop Scand 1993a;Suppl 251:78-80.

Postacchini F, Cinotti G, Perugia D, Gumina S. The surgical treatment of central lumbar stenosis: multiple laminotomy compared with total laminectomy. J Bone Joint Surg [Br] 1993b;75-B:386-92.

Postacchini F, Ripani M, Carpano S. Morphometry of the lumbar vertebrae: an anatomic study in two Caucasoid ethnic groups. Clin Orthop 1983;172:296-303.

Senegas J, Etchevers JP, Vital JM, Baulny D, Grenier F. Le récalibrage du canal lombaire, alternative à la laminectomie dans le traitment des sténoses du canal lombaire. Rev Chir Orthop 1988;74:15-22.

Tile M, McNeil SR, Zarins RK, Pennal GF, Garside SH. Spinal stenosis: results of treatment. Clin Orthop 1976;115:104-8.

Verbiest H. Fallacies of the present definition, nomenclature and classification of the stenoses of the lumbar vertebral canal. Spine 1976;1:217-25.

Verbiest H. Results of surgical treatment of idiopathic developmental stenosis of the lumbar vertebral canal: a review of twenty-seven years' experience. J Bone Joint Surg [Br] 1977;59-B:181-8.

Wiltse LL. Alar transverse process impingement of the L5 spinal nerve: the far out syndrome. Spine 1984;9:31-41.

Young S, Veerapen R, O'Laoire SA. Relief of lumbar canal stenosis using multilevel subarticular fenestrations as an alternative to wide laminectomy: preliminary report. Neurosurgery 1988;23:628-33. 